\title{
The Effect of Smoking on Carbon Monoxide Respiration among Active Smokers in Palembang City, Indonesia
}

\author{
Rico Januar Sitorus ${ }^{1}$, Imelda G Purba ${ }^{2}$, Merry Natalia ${ }^{3}$, Kraichat Tantrakarnapa ${ }^{4}$
}

\author{
${ }^{1}$ Department of Epidemiology, Faculty of Public Health, Universitas Sriwijaya, Indonesia \\ 2Department of Environmental and Occupational Health, Universitas Sriwijaya, Indonesia \\ ${ }^{3}$ Staff of Port Health Office, Ministry of Health, Palembang, Indonesia \\ 4Department of Social and Environmental Medicine, Faculty of Tropical Medicine, Mahidol University, Bangkok, Thailand
}

\begin{abstract}
Smoking leads to disease and disability as well as harms nearly every organ of the body. Furthermore, tobacco-smoking is known to cause pulmonary dysfunction and lead to complications, pain, or even death. This study aimed to measure the risk factors for the respiration of carbon monoxide among smokers. A cross-sectional design was implemented by involving 156 smokers in Karyajaya Subdistrict, Palembang City. The dependent variable was carbon monoxide levels (ppm), while the independent variables were smoking frequency, duration, and the last period of smoking. The carbon monoxide levels (ppm) measured with a PiCO + Smokerlyzer $囚$ device from Bedfont Scientific Limited were the study tool and the independent variables of the questionnaire. The Pearson Correlation and multiple linear regression were used for the analysis. The multiple linear regression analysis results revealed that smoking duration assessment is related to carbon monoxide respiration after controlling smoking frequency, the last period of smoking, and the distance of residence to sources of exposure. The smoker's respiration of carbon monoxide level was $72.5 \%$ influenced by the duration, frequency, last period of smoking, and distance of residence to sources of exposure. Reducing the frequency of smoking and stopping may prevent and control carbon monoxide respiration.
\end{abstract}

Keywords: carbon monoxide level, smoking duration, swamp, tobacco smoke

\section{Introduction}

Smoking is a risk factor for several diseases, including cardiovascular disease, chronic obstructive pulmonary disease, and lung cancer. However, the specific role of the smoke of cigarette in the disease remained unclear. Furthermore, it is a complex aerosol made up of thousands of chemicals compounds identified as carcinogens. ${ }^{1}$

One of the more toxic substances in the tobacco gas phase is Carbon monoxide (CO), which can cause tissue hypoxia toxicity because it can bind 200 to 240 times the amount of oxygen to hemoglobin that can decrease oxygen transport capacity and inhibit the release of oxygen in cells. ${ }^{2}$ Furthermore, $\mathrm{CO}$ can also cause cardiovascular dysfunctions such as angina, myocardial infarction, arrhythmias, left ventricular dysfunction, myocardial transient fainting, cardiogenic shock, and sudden death. ${ }^{3}$

The acute effects of cigarette smoke containing $\mathrm{CO}$ influenced the biochemical conditions of the lungs, which can lead to lung disease. ${ }^{1,4}$ The $\mathrm{CO}$ content exhaled by the body is influenced by physiological factors and disease in which endogenous and exogenous factors influ- ence the amount of carbon monoxide stored in the body. ${ }^{5}$ Furthermore, its poisoning occurred in different populations and was influenced by the type of work, and the jobs at risk were workers exposed to the gas. ${ }^{6}$

The $\mathrm{CO}$ monitoring each individual can identify populations at high risk for respiratory diseases related to air pollution. Exposure to $\mathrm{CO}$ has been shown to correlate with concentrations of particles that can cause respiratory problems, lung disease, increase the risk of asthma, and even death. ${ }^{7-9}$ Lung disease and respiratory disorders can cause disability and poor quality of life. ${ }^{10,11}$ People that survive severe $\mathrm{CO}$ poisoning may suffer long-term health problems. Furthermore, the $\mathrm{CO}$ is quick to connect with the red blood cells but slow to exit the body. ${ }^{12}$ The average $\mathrm{CO}$ level of smokers was higher than that of non-smokers, proving that exposure to cigarettes affects biological conditions in the body. ${ }^{13}$

The acute effects of smoking influence the biochemical conditions in the lungs. ${ }^{14}$ This study played an important role to determine the levels of $\mathrm{CO}$ in the lungs of active smokers, which accumulates over a long period of time. The main objective of this study was to measure ac-

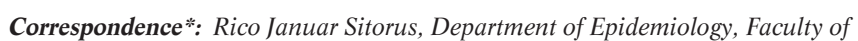
Public Health, Sriwijaya University, Kampus Universitas Sriwijaya Indralaya, Ogan Ilir District, South Sumatera Province, Indonesia, E-mail: rico_januar@fkm.unsri.ac.id, Phone: +62 81367712221
Received : September 03, 2019

Accepted : February 05, 2021

Published: May 28, 2021 
tive smokers' $\mathrm{CO}$ levels in the respiratory cavity and to find out the factors associated with high levels of CO.

\section{Method}

In this study, a cross-sectional design was created in which the duration of smoking and the CO levels of the respiratory tract were measured simultaneously. The population was all households in the Karyajaya Primary Health Care working area, consisting of 40 neighborhood groups with a total population of 2,631 residents and is located near the river bank with house-like features.

The Probability Proportionate to Size (PPS) sampling method and systematic random sampling were applied. The sampling frame consists of households in each neighborhood group, with the total sample of 156 respondents.

There were several inclusion criteria, such as household members that smoke at least for six months with two active smokers living in one house. This criteria involves the choosing of only one person-the oldest one, also family members that were not diagnosed with acute respiratory tract infections and pulmonary tuberculosis.

A questionnaire and a portable $\mathrm{PiCO}+$ Smokerlyzer ${ }^{\circledR}$ device from Bedfont Scientific Limited were used as a study instrument. The measurements of $\mathrm{CO}$ levels in the respiration were carried out by how the respondent breathed, as usual, inhaled, and held his breath for 20 seconds. After holding his breath, the respondent immediately exhaled on the measuring device until it was lifted. Within a few seconds, the measurement device would show $\mathrm{CO}$ levels on the screen and were calculated using part-per-million (ppm).

The analysis started with a data completion by editing, coding, and entering. The refined was further analyzed by using the univariate, bivariate, and multivariate methods. Furthermore, univariate analysis was conducted to describe the characteristics and distribution of each variable, gender, education, job status, income level, and cigarette types.

The gender variable was divided into two categories of men and women. The education variable was divided into no school education, graduated from elementary school, graduated from junior high school, and graduated from senior high school. The job-status variable was divided into unemployment, student, driver, parking attendant, factory worker, mechanic, merchant, labor, teacher, and employee. The income level variable was divided into less than Guaranteed Minimum Income (GMI), and $\geq$ GMI. The cigarette types variable was divided into Clove and White. The measurement results variable was divided into smoking duration, frequency, age, a distance of residence to sources of exposure, last period of smoking, age of the first period of smoking, and family income with numerical data. The bivariate statistical analysis using correlation test with the model selected candidates only variable with significance $<0.25$ to be continued into the multivariate analysis using multiple linear regressions test. This study passed the ethical review of the Faculty of Public Health Universitas Sriwijaya with the number of 124/UN9.1.10/KKE/2019.

\section{Results}

Based on the data recorded in Table 1, the respondents were 156 people with the characteristics of the majority of men being $98.1 \%$, the level of education graduating from elementary school was $41.7 \%$, employed $41.7 \%$, income level below the regional minimum wage at $71.8 \%$, and smoking clove cigarettes at $83.3 \%$. The average level of $\mathrm{CO}$ was $12.38 \mathrm{ppm}$ with the highest level of $23 \mathrm{ppm}$, the average frequency of smoking was 13 cigarettes in the last three days, the average smoking period was 16 years, and the last period of smoking was 128 minutes ago, as recorded in Table 2.

The result of the correlation analysis showed a positive correlation between the duration of smoking, the age, and the $\mathrm{CO}$ values in the respiratory cavity of smokers with a moderate correlation strength. The correlation between smoking frequencies - the level of income with $\mathrm{CO}$

Table 1. Characteristics of Active Smoker Respondents in Palembang City ( $n=156)$

\begin{tabular}{llrr}
\hline Variable & Category & $\mathbf{n}$ & $\%$ \\
\hline \multirow{3}{*}{ Gender } & Male & 153 & 98.1 \\
& Female & 3 & 1.9 \\
& Not having school & 4 & 2.6 \\
& Graduated from elementary school & 65 & 41.7 \\
& Graduated from junior high school & 45 & 28.8 \\
& Graduated from senior high school & 42 & 26.9 \\
& Unemployment & 12 & 7.7 \\
& Student & 2 & 1.3 \\
& Driver & 16 & 10.3 \\
& Parking attendant & 4 & 2.6 \\
& Factory worker & 33 & 21.2 \\
& Mechanic & 2 & 1.3 \\
& Merchant & 7 & 4.5 \\
& Labor & 65 & 41.7 \\
& Teacher & 1 & 0.6 \\
& Employee & 14 & 9.0 \\
& L Guaranteed Minimum Income (GMI) & 112 & 71.8 \\
& C Guaranteed Minimum Income (GMI) & 44 & 28.2 \\
& Clove & 130 & 83.3 \\
& White & 26 & 16.7
\end{tabular}

Table 2. Distribution of Active Smokers Respondents in Palembang City $(n=156)$

\begin{tabular}{|c|c|c|c|c|}
\hline \multirow{2}{*}{ Variable } & \multirow{2}{*}{ Mean } & \multirow{2}{*}{ Median } & \multicolumn{2}{|c|}{$95 \% \mathrm{CI}$} \\
\hline & & & Lower & Upper \\
\hline Carbon monoxide levels (ppm) & 12.38 & 13 & 11.39 & 13.36 \\
\hline Smoking frequency (last 3 days) & 13.12 & 12 & 11.87 & 14.37 \\
\hline Smoking duration (year) & 16.49 & 16 & 15.26 & 17.72 \\
\hline Last time of smoking (minute) & 128.69 & 127 & 101.37 & 156 \\
\hline
\end{tabular}

Note: $\mathrm{CI}=$ Confidence Interval 
levels showed a positive correlation with strong correlation strength. The correlation between the first period of smoking showed a significant negative correlation with medium correlation strength, while the distance where the respondent lived to the factory showed a negative correlation with the weak correlation strength. The last period of smoking showed a negative correlation with strong correlation strength, as shown in Table 3.

Multiple linear regression results showed that duration of smoking, smoking frequency, last hour of smoking, and distance from home to sources of exposure are variables that predict smoker monoxide carbon levels. The coefficient of determination $\mathrm{R}$ squared (Table 4) showed the value of 0.725 , which means that the regression model obtained can explain $72.5 \%$ of the variation smoker monoxide concentration level. This regression equation model also fulfilled the assumptions such as existence with residual value (mean) 0.0001 , linearity with ANOVA value obtained $0.0001<0.05$. The homoscedasticity, which is a non-patterned scattering point and spreads evenly around the zero points in such a way that multivariate normality also fulfills assumptions. There was no VIF value for each variable in the model that exceeded 10 . Therefore, there was no multicollinearity between the independent variables. Assumptions that meet the requirements stated that the regression model is fit (Table 4). Carbon Monoxide Levels of Smokers $=8.326$ +0.092 (Smoking Duration) + 0.453 (Smoking Frequency) + (-0.014) Last Time of Smoking + (- 0.014) Distance of Residence to Sources of Exposure.

\section{Discussion}

This study showed that most of those on low incomes or below the district salary were $71.8 \%$ and had smoking

Table 3. Correlation Analysis of Independent Variables with Carbon Monoxide Level

\begin{tabular}{lrc}
\hline Variable & p-value & Correlation Coefficient \\
\hline Smoking duration & 0.0001 & 0.40 \\
Smoking frequency & 0.0001 & 0.77 \\
Age & 0.0001 & 0.28 \\
Distance of residence to sources of exposure & 0.029 & -0.17 \\
Last time of smoking & 0.0001 & -0.62 \\
Ages of the first time smoking & 0.001 & -0.28 \\
Family income & 0.042 & 0.60 \\
\hline
\end{tabular}

habits, which increased the level of carbon monoxide in the respiratory cavity. The human respiratory tract would receive between 15,000 and 40,000 $\mu \mathrm{g}$ particulates matter with one cigarette. Long-term smoking habits affect the health of healthy people and those that are already sick, especially in the respiratory system. The carbon monoxide component in cigarette smoke contained 26\%.15 Exposure to cigarette smoke increased carbon monoxide levels in breathing activity in such a way that it can increase the risk of sleep apnea, asthma, and pulmonary tuberculosis. ${ }^{16}$

The results showed that the average level of $\mathrm{CO}$ was 12.38. Teenagers that smoked between the age of 13-17 years had carbon monoxide levels of $2.14 \mathrm{ppm}$ and 8 ppm. ${ }^{17}$ The average CO level was higher for smokers compared to non-smokers. ${ }^{18}$ This study was in line with Sandberg, et al. ${ }^{19}$ study result, which revealed that the smokers smoking the last eight hours had higher CO levels than those smoking more than eight hours and nonsmokers. The frequency of smoking correlates with the $\mathrm{CO}$ values. The frequency of the correlation of smoking with the $\mathrm{CO}$ values correlates with weaknesses. ${ }^{19}$

Increasing the levels of $\mathrm{CO}$ smokers also correlated with old smokers. The longer a person smokes, the higher the $\mathrm{CO}$ level. Furthermore, $\mathrm{CO}$ can be synthesized endogenously with several physiological effects resulting in significant morbidity and mortality. ${ }^{20,21}$ Another study also stated that the smokers of 50 packs and 20 packs per year had higher levels of $\mathrm{CO}$ and had a higher risk for respiratory problems. ${ }^{22}$

The results showed that the average level of $\mathrm{CO}$ was 12.38. Teenagers that smoke between the age of 13 and 17 had carbon monoxide levels of 2.14 ppm and working totals of 8 ppm. ${ }^{17}$ An individual that had been smoking for a long time would be positively correlated to the incidence of myocardial infarction because carbon monoxide was considered a pollutant and toxic that can bind to the heme-containing iron from hemoglobin. ${ }^{2}$

This study revealed that there was a positive correlation between the smoking duration and $\mathrm{CO}$ levels. Exhaled carbon monoxide ( $\mathrm{CO}$ ) levels were positively associated with smoking. Active smokers have higher $\mathrm{CO}$ levels for both men and women than those that never smoke. ${ }^{23}$

The results showed a positive correlation between the

Table 4. Final Model of Multiple Linear Regression

\begin{tabular}{|c|c|c|c|c|c|c|c|c|}
\hline Variable & B-value & p-value & VIF & Residual (Mean) & R Square & ANOVA & Durbin-Watson & Constanta \\
\hline Smoking duration & 0.092 & 0.02 & 1.291 & & & & & \\
\hline Smoking frequency & 0.453 & 0.0001 & 1.418 & & & & & \\
\hline Last time of smoking & -0.014 & 0.0001 & 1.136 & 0.001 & 0.725 & 0.0001 & 2.066 & 8.326 \\
\hline $\begin{array}{l}\text { Distance of residence to sources } \\
\text { of exposure }\end{array}$ & -0.002 & 0.002 & 1.101 & & & & & \\
\hline
\end{tabular}

Notes: VIF = Variance Inflating Factor; ANOVA = Analysis of Variance 
smoking frequencies with carbon monoxide levels in the respiratory cavity. This research was in line with Zhang, et al., ${ }^{23}$ which stated that the average CO levels were higher in people who smoke cigarettes every day than non-smokers. The respondent's living near the industry (factory) and landfills are exposed to higher level of $\mathrm{CO}$ of about $23.1 \%$. Furthermore, $\mathrm{CO}$ exposure can also increase due to environmental pollution and living close to the source of pollution. The last time of smoking was negatively correlated with $\mathrm{CO}$ levels in the respiratory cavity. The longer the $\mathrm{CO}$ level was measured in the lungs of a smoker, the lower the level of $\mathrm{CO}$ level. People that smoke had higher levels of CO than non-smokers. ${ }^{23}$

The strength of this study was to determine the levels of respiratory carbon monoxide in smokers. The measurements were made directly using a reliable measuring instrument with a valid result and the data can be used to control diseases in smokers. The weakness of the chosen design was the lack of strong causality between cigarette smoke exposure and respiratory $\mathrm{CO}$ levels among smokers.

\section{Conclusion}

The duration of smoking influences the respiratory carbon monoxide content of $72.5 \%$ in smokers. Other factors influence the frequency of smoking, the last period of smoking, the distance of residence to sources of exposure, and $28.5 \%$.

\section{Recommendation}

Reducing the frequency of smoking and even stopping smoking may prevent and control the respiratory of carbon monoxide.

\author{
Abbreviations \\ CO: Carbon monoxide; PPS: Probability Proportional to Size; PPM: \\ Part-Per-Million; VIF: Variance Inflating Factor; GMI: Guaranteed \\ Minimum Income; CI: Confidence Interval.
}

\section{Ethics Approval and Consent to Participate}

This research has passed the ethical review in the Faculty of Public Health with the number of 124/UN9.1.10/KKE/2019.

\section{Competing Interest}

The author declares that there are no significant competing financial, professional, or personal interests that might have affected the performance or presentation of the work described in this manuscript.

\section{Availability of Data and Materials}

Data and all related materials from this study are available by the first author.

\section{Authors' Contribution}

RJS designed the study, developed data instrument for collecting the data, data analysis, and drafted the manuscript. Other authors assisted in the analyzing and interpreting data, finding the supporting journals, correcting the writing procedures, and finalizing manuscripts.

\section{Acknowledgment}

The authors express profound gratitude to Universitas Sriwijaya, Karyajaya Primary Health Care, and all study's team members.

\section{References}

1. Liu J, Liang Q, Frost-Pineda K, Muhammad-Kah R, Rimmer L, Roethig H, et al. Relationship between biomarkers of cigarette smoke exposure and biomarkers of inflammation, oxidative stress, and platelet activation in adult cigarette smokers. Cancer Epidemiology, Biomarkers \& Prevention. 2011; 20 (8): 1760-9.

2. Lee F-Y, Chen W-K, Lin C-L, Kao C-H. Carbon monoxide poisoning and subsequent cardiovascular disease risk: a nationwide populationbased cohort study. Medicine (Baltimore). 2015; 94 (10): e624.

3. Garg J, Krishnamoorthy P, Palaniswamy C, Khera S, Ahmad H, Jain $\mathrm{D}$, et al. Cardiovascular abnormalities in carbon monoxide poisoning. American Journal of Therapeutics. 2018; 25 (3): e339-48.

4. Bagaitkar J, Demuth DR, Daep CA, Renaud DE, Pierce DL, Scott DA. Tobacco upregulates $\mathrm{P}$. gingivalis fimbrial proteins which induce TLR2 hyposensitivity. PLoS One. 2010; 5 (5).

5. Owens EO. Endogenous carbon monoxide production in disease. Clinical Biochemistry. 2010; 43 (15): 1183.

6. Brvar M, Luzar B, Finderle Ž, Šuput D, Bunc M. The time-dependent protective effect of hyperbaric oxygen on neuronal cell apoptosis in carbon monoxide poisoning. Inhalation Toxicology. 2010; 22 (12): 1026-31.

7. Moore E, Chatzidiakou L, Kuku M-O, Jones RL, Smeeth L, Beevers S, et al. Global associations between air pollutants and chronic obstructive pulmonary disease hospitalizations. A systematic review. Annals of the American Thoracic Society. 2016; 13 (10): 1814-27.

8. McCracken JP, Schwartz J, Diaz A, Bruce N, Smith KR. Longitudinal relationship between personal $\mathrm{CO}$ and personal PM2.5 among women cooking with woodfired cookstoves in Guatemala. PLoS One. 2013; 8 (2).

9. McLeish AC, Zvolensky MJ. Asthma and cigarette smoking: a review of the empirical literature. ournal of Asthma. 2010; 47 (4): 345-61.

10. Santus P, Bassi L, Radovanovic D, Airoldi A, Raccanelli R, Triscari F, et al. Pulmonary rehabilitation in COPD: a reappraisal (2008-2012). Pulmonary Medicine. 2013.

11. Sahin H, Naz I, Varol Y, Aksel N, Tuksavul F, Ozsoz A. COPD patients with severe diffusion defect in carbon monoxide diffusing capacity predict a better outcome for pulmonary rehabilitation. Revista Portuguesa de Pneumologia (English Ed.). 2016; 22 (6): 323-30.

12. Centers for Disease Control and Prevention. Carbon monoxide poisoning. National Environmental Public Health Tracking Network, Centers for Disease Control and Prevention; 2016.

13. Javors MA, Hatch JP, Lamb RJ. Sequential combination of self-report, breath carbon monoxide, and saliva cotinine to assess smoking status. Drug and Alcohol Dependence. 2011; 113 (2): 242-4.

14. Koczulla A-R, Noeske S, Herr C, Jörres RA, Römmelt H, Vogelmeier $\mathrm{C}$, et al. Acute and chronic effects of smoking on inflammation mark- 
ers in exhaled breath condensate in current smokers. Respiration. 2010; 79 (1): 61-7.

15. Sangani RG, Ghio AJ. Lung injury after cigarette smoking is particle related. International Journal of Chronic Obstructive Pulmonary Disease. 2011; 6: 191.

16. Jayes L, Haslam PL, Gratziou CG, Powell P, Britton J, Vardavas C, et al. SmokeHaz: systematic reviews and meta-analyses of the effects of smoking on respiratory health. Chest. 2016; 150 (1): 164-79.

17. Nur Atikah AH, Wee LH, Nur Zakiah MS, Chan CMH, Mohamed Haniki NM, Swinderjit JS, et al. Factors associated with different smoking statuses among Malaysian adolescent smokers: a cross-sectional study. BMC Public Health. 2019; 19 (4) :579.

18. Maga M, Janik MK, Wachsmann A, Chrząstek-Janik O, Koziej M, Bajkowski M, et al. Influence of air pollution on exhaled carbon monoxide levels in smokers and non-smokers. A prospective cross-sectional study. Environmental Research. 2017; 152: 496-502.

19. Sandberg A, Sköld CM, Grunewald J, Eklund A, Wheelock ÅM. Assessing recent smoking status by measuring exhaled carbon monoxide levels. PLoS One. 2011; 6 (12).
20. Hampson NB, Piantadosi CA, Thom SR, Weaver LK. Practice recommendations in the diagnosis, management, and prevention of carbon monoxide poisoning. American Journal of Respiratory and Critical Care Medicine. 2012; 186 (11): 1095-101.

21. Milne B, Vandenkerkhof E, Phelan R, Brien J, Forkert L, Nakatsu K. Does carbon monoxide play a role in cigarette smoke dependence? Addiction Research \& Theory. 2012; 20 (2): 138-44.

22. Musallam KM, Rosendaal FR, Zaatari G, Soweid A, Hoballah JJ, Sfeir PM, et al. Smoking and the risk of mortality and vascular and respiratory events in patients undergoing major surgery. JAMA Surgery. 2013; 148 (8): 755-62.

23. Zhang Q, Li L, Smith M, Guo Y, Whitlock G, Bian Z, et al. Exhaled carbon monoxide and its associations with smoking, indoor household air pollution and chronic respiratory diseases among 512,000 Chinese adults. International Journal of Epidemiology. 2013; 42 (5): 1464-75. 